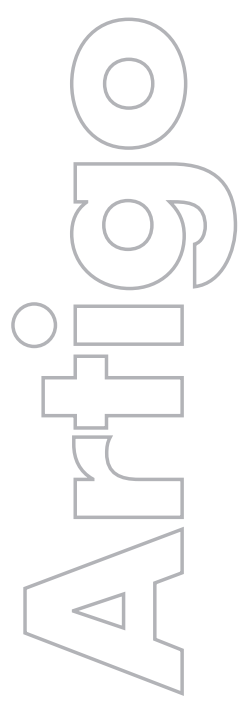

revista

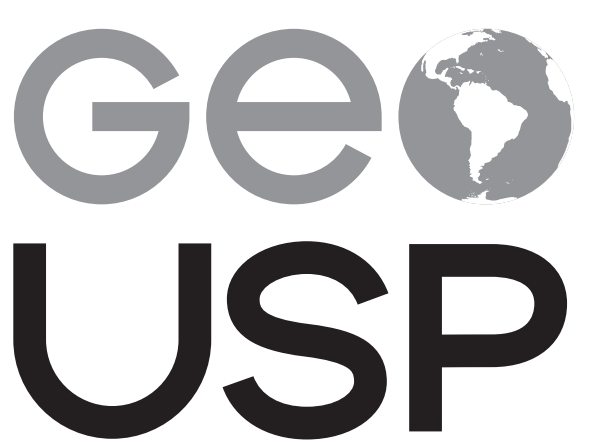

espaço e tempo

Volume $21 \cdot n^{\circ} 2$ (2017)

ISSN 2179-0892
Requalificação pela desqualificação: o discurso da reurbanização no "novo" Rio Vermelho

Roney Gusmão

UFRB

p. $531-549$

Como citar este artigo:

GUSMÃO, R. Requalificação pela desqualificação: o discurso da reurbanização no "novo" Rio Vermelho. Geousp - Espaço e Tempo (Online), v. 21, n. 2, p. 531-549, agosto. 2017. ISSN 2179-0892.

Disponível em: < http://www.revistas.usp.br/geousp/ article/view/121837>. doi: 10.11606/issn.2179-0892. geousp.2017.121837.

\section{(c) $(1) \Theta$}

Este artigo está licenciado sob a Creative Commons Attribution 4.0 License. 


\title{
Requalificação pela desqualificação: o discurso da reurbanização no "novo" Rio Vermelho
}

\section{Resumo}

O presente artigo é produto de pesquisas que fizemos sobre as obras de requalificação do bairro Rio Vermelho, em Salvador. Nessa investigação, empenhamo-nos em problematizar os impactos do enobrecimento em curso no bairro, sobretudo para a população de menor poder aquisitivo, que tem sido alijada do direito de participar dos projetos da prefeitura. As intervenções urbanas feitas no Rio Vermelho mostram-se orquestradas pela mesma lógica que gerencia a cidade-empresa, onde (re)estruturas são balizadas para atender a expectativas de investidores e consumidores, negando a prerrogativa democrática do direito à cidade.

Palavras-chave: Rio Vermelho. Requalificação urbana. Gentrificação. Exclusão. Higienismo social.

\section{Requalification by disqualification: the discourse of reurbanization in the "new" Rio Vermelho}

\begin{abstract}
This article is a product of a research conducted about the rehabilitation works of Rio Vermelho neighborhood, in Salvador. In this investigation we have beenimbued into question the impacts of gentrification that is having in the neighborhood, especially for people with lower purchasing power. Urban interventions in Rio Vermelho show up orchestrated by the same logic that manages the city-company where (re)structures are buoyed by meeting the expectations of investors and consumers, denying the right to the city as a democratic prerogative.
\end{abstract}

Keywords: Rio Vermelho. Urban requalification. Gentrification. Exclusion. Social hygiene.

\section{Introdução}

"Isso aqui era terra de ninguém", afirmou um membro da associação de moradores do Rio Vermelho ao se referir ao bairro antes das intervenções realizadas pela prefeitura municipal de Salvador. Mas, quem é "ninguém"? Personificam-se como "alguém" apenas os cidadãos que assumem 
o papel de investidores/consumidores na esfera capitalista? Para problematizar essas questões, é útil observar que a cisão do binômio público x privado foi acentuada no curso da história, especialmente com o advento do sistema capitalista. A ideia de público como lugar de desmando e caos foi ainda mais reforçada por políticas neoliberais que, no Brasil, se tornaram muito fecundas a partir dos anos 1980. Diante disso, a vulga expressão "terra de ninguém" ilustra a ideia de que a ordem residiria apenas na autoridade chancelada ao poder privado, ao passo que o "ninguém" que usufrui do espaço público o desqualifica à medida que demonstra incapacidade de uso racional.

No curso da pesquisa que inspirou este artigo, muito dos sujeitos que entrevistamos manifestaram pouco esmero para com a "terra" pública, demonstrando o quanto apelos ideológicos neoliberais têm sido fertilizados em meio à opinião popular, precisamente porque insiste em justificar as requalificações do espaço urbano pela desqualificação e sucateamento de tudo que seja público e popular.

Essa realidade tem sido muito nítida no campo empírico ao qual esta pesquisa se ocupa, sobretudo por conta do processo higienista fortemente implantado pela administração pública local em trechos privilegiados da orla soteropolitana. $\bigcirc$ Rio Vermelho é porção emblemática do que afirmamos. Amplamente conhecido pela movimentação noturna, o bairro se tornou lugar propício para instalação de teatros, bares, boates, restaurantes, lanchonetes, botecos, além de uma extensa rede hoteleira. A localização faz dele um dos bairros de grande significado histórico para o turismo em Salvador, chamando atenção de turistas que trafegam no trajeto da orla no sentido aeroporto-centro. Além disso, residiram no Rio Vermelho diversos expoentes da cultura baiana: Jorge Amado, Gal Costa, Caetano Veloso, Carlinhos Brown e Mário Cravo são alguns desses ícones que já viveram nas mediações do bairro.

\section{Figura 1 - Mapa do bairro Rio Vermelho na cidade de Salvador-BA}

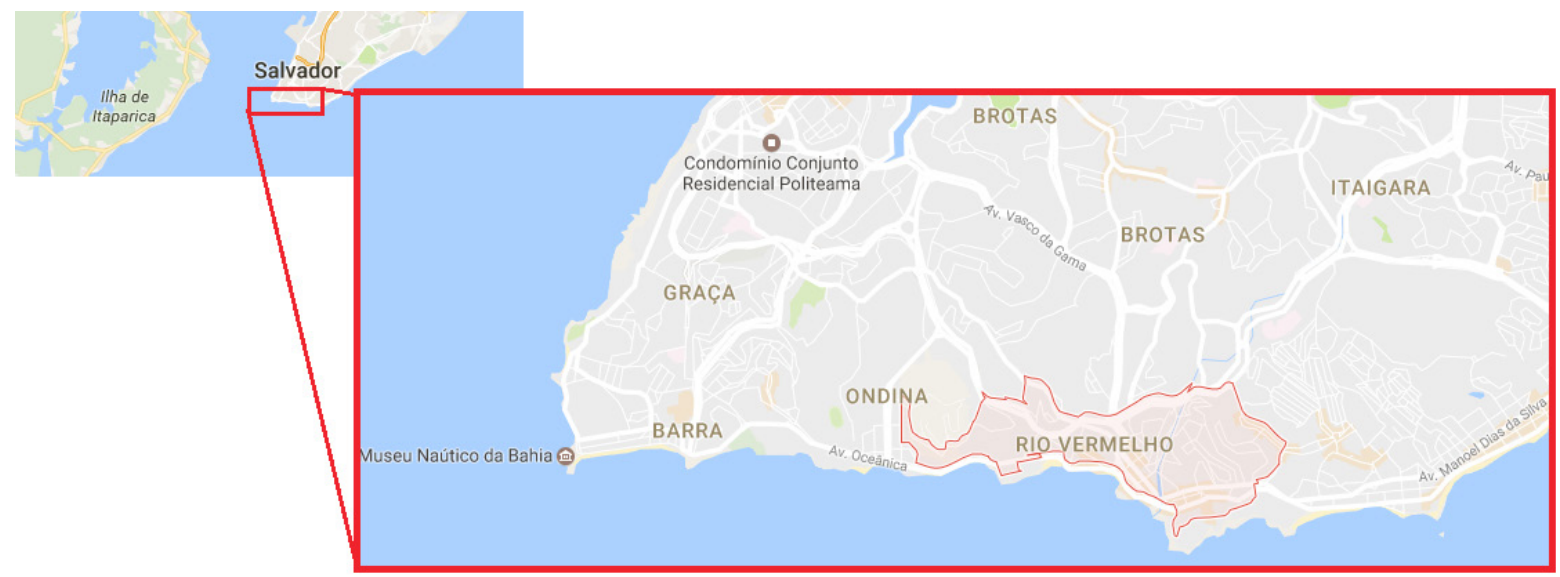

fonte: Google Maps ([s.d.]).

Acrescenta-se a isso o fato de que o Rio Vermelho seja palco de múltiplas manifestações identitárias, que variam desde rituais religiosos (com ênfase à festa de Yemanjá), até baladas gays e festivais populares. Nessa miscelânea de formas expressivas, o Rio Vermelho se tornou atraente para negócios voltados ao turismo, seduzindo, por tabela, cobiçosos empreendedores do ramo imobiliário.

Desde meados do século XX, a orla do Rio Vermelho tem passado por um severo processo de apropriação, com a vertiginosa edificação de prédios de alto padrão, fato que resultou numa acelerada verticalização na costa, resultando na acentuação do desconforto térmico no 
interior do bairro. Não obstante, enquanto a orla foi apropriada por prédios monumentais, o entorno do bairro foi sendo cada vez mais ocupado por favelas, refletindo o modelo desigual de desenvolvimento econômico implantado na cidade no decorrer do período supracitado.

Concomitante ao aprofundamento da desigualdade social em Salvador, a partir do fim do século XX, a cultura baiana foi sendo maciçamente usada como mecanismo de atração turística, fato que acirrou o marketing a serviço do turismo, agudizando a disputa capitalista por alguns trechos mais representativos do espaço urbano soteropolitano. Ora, é válido lembrar que os signos da cultura baiana, tão intensamente divulgados pela mídia, frequentemente têm no espaço citadino uma fonte de inspiração para narrativas de identidade. São morros, ladeiras, casarões, praias, por vezes invocadas por seu nome: Pelô, Itapuã, Farol da Barra, avenida Sete e tantos outros palcos para expressões de baianidade.

No presente texto não queremos entrar na ambivalente construção ideológica da "baianidade", mas o que nos cabe por ora perceber é o quanto os componentes dos cenários urbanos são tornados artefatos pelo mercado, retroalimentando a indústria do turismo local. E, nessa oportunidade, são agravadas disputas pela subsistência num contexto desigual de inserção nos muitos setores do mercado, eclodindo em conflitos e movimentos de resistência nos ambientes mais contestados.

Chegando ao século XXI, o Rio Vermelho tem estado sob os holofotes dessa disputa entre forças desiguais. Quando no ano de 2016, a administração municipal inaugurou parte da revitalização no bairro, a exclusão de ambulantes foi motivo de alerta diante dos reais intentos do projeto burguês para o espaço urbano local. Diversas placas com o slogan "Bem-vindo ao novo Rio Vermelho", "O Rio Vermelho voltou a sorrir" ou "Viva a cultura" foram espalhadas, explicitando o nexo discursivo contido nas obras de requalificação.

\section{Figura 2 - Fotografia disponível na homepage oficial da prefeitura de Sal-} vador saudando o "novo" Rio Vermelho. A imagem revela o calçamento no Largo da Mariquita, inspirado no estilo shopping-center, com supressão de áreas verdes e marcante higiene social

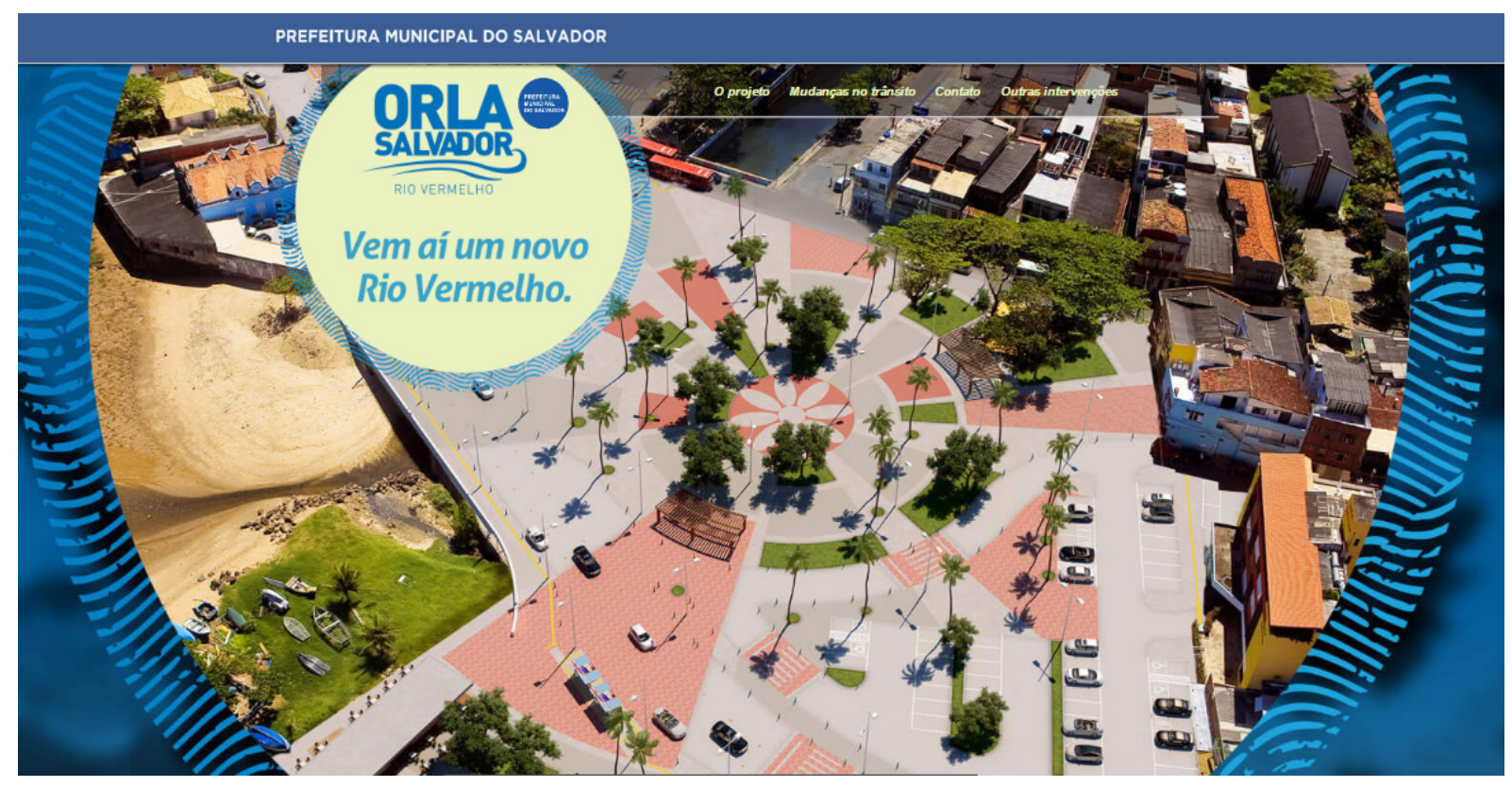

fonte: Prefeitura Municipal de Salvador ([s.d.]). 


\section{Figura 3 - Placas da prefeitura municipal de Salvador na orla anunciam o "novo" Rio Vermelho}
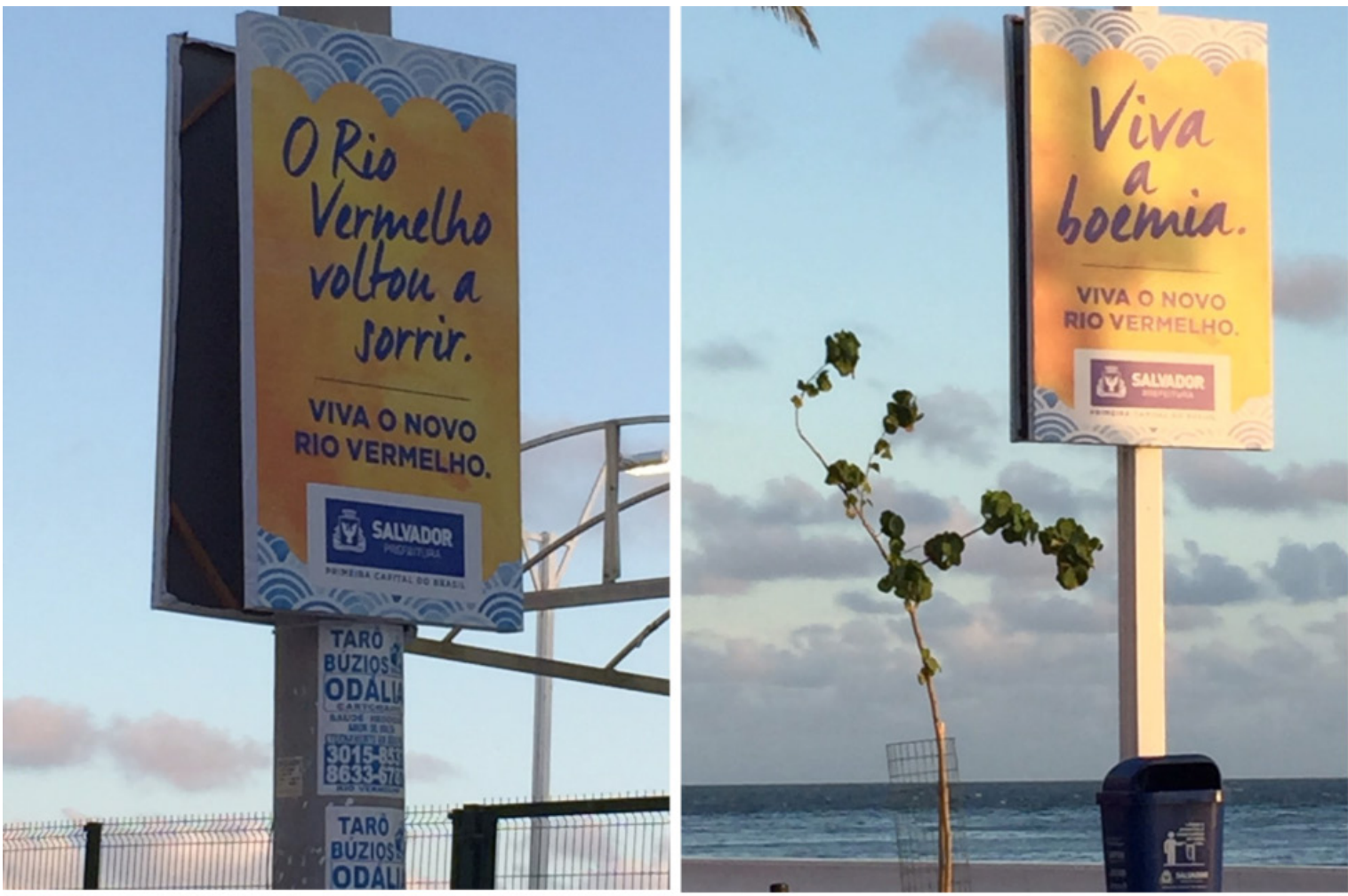

fonte: Acervo pessoal.

Ao olhar desatento, a superfície do bairro parece ter sido de fato melhorada: ampliação dos calçadões, iluminação reforçada de praças e vias, reforma de ciclovias e reparo de quadra pública; entretanto os danos sociais das intervenções, bem como sua incapacidade de amenizar problemas estruturais do bairro, atestaram a prontidão da prefeitura municipal em cumprir as expectativas do grande capital para o Rio Vermelho.

A lógica parece bastante simples: desqualificar o "velho" Rio Vermelho, salientando as empreitadas da prefeitura com vistas a higienizar socialmente o bairro e impor formas autoritárias de apropriação do solo urbano. Muito embora esse raciocínio seja escancarado na postura repressiva da prefeitura, que expulsou comerciantes populares e impôs um ethos fortemente equalizado aos padrões estéticos elitistas, o tema ainda divide opiniões.

Parte daqueles que residem nas mediações dos trechos requalificados se sentem satisfeitos com as mudanças. Ao se referirem ao Mercado do Peixe, que foi privatizado pela prefeitura e reocupado por grandes empresários do ramo gourmet, alguns salientam:

Felizmente a prefeitura destruiu aquela excrescência que era o Mercado do Peixe, um antro de drogados e putas (Manoel, 70 anos).

Esse bando de sacizeiro' foi removido daqui e agora quer voltar a todo custo, vandalizando as ruas, fazendo baderna e protestos (Sandro, 68 anos).

$\bigcirc$ prefeito quer o bem desta cidade. Somente os vândalos não veem porque eles querem a bagunça e a vagabundagem (Sérgio, 45 anos).

Gíria usada em Salvador para se referir aos usuários de craque, numa alusão ao personagem folclórico Saci. 
As palavras dos entrevistados são bastante emblemáticas para demonstrar a repulsa criada contra a "coisa pública". Soma-se a isso a pouca importância dada aos trabalhadores expulsos das áreas gentrificadas, fato que revela a individualização como um dos efeitos colaterais de uma sociedade brutalmente desigual.

Numa reflexão bastante oportuna, Bauman (2001) considera que a individualização é uma característica muito recorrente nas sociedades pós-modernas. A luta pela sobrevivência na sociedade, para o autor, tem se tornado cada vez mais um enfrentamento solitário, fortalecendo a percepção do outro como um rival a ser ignorado ou, quando possível, eliminado.

O "cidadão" é uma pessoa que tende a buscar seu próprio bem-estar através do bem-estar da cidade - enquanto o indivíduo tende a ser morno, cético ou prudente em relação à "causa comum", ao "bem comum", à "boa sociedade" ou à "sociedade justa". Qual é o sentido de "interesses comuns" senão permitir que cada indivíduo satisfaça seus próprios interesses? (Bauman, 2001, p. 49-50).

O raciocínio individualista se recrudesce à medida que a contestação pelo direito à cidade se torna uma empreitada pessoal e não coletiva. Com isso, ao perceberem-se individualmente contemplados pelas reformas nas ruas do Rio Vermelho, alguns entrevistados parecem ignorar os custos sociais e as exclusões severas proporcionadas pela requalificação. A sensação de favorecimento individual se sobrepõe a toda forma de solidariedade àqueles que foram banidos pelo grande capital.

Além das opiniões acima mencionadas, também foi nossa preocupação observar as formas de resistência que ganharam as ruas, anunciando o descontentamento com as regras unilaterais impostas na (re)construção da cidade. Embora falemos de mecanismos dissimulados de apropriação do Rio Vermelho, diversos sujeitos passaram a reivindicar o direito de participar das decisões tomadas pela prefeitura, fato que reforça o quanto a cidade é lócus de relações sociais altamente conflitivas e permeadas de representações múltiplas sobre existir socialmente.

Com vistas a proceder esta investigação, além da análise teórica sobre temáticas urbanas, partimos a campo, tanto para observar as intervenções, como para dialogar com os sujeitos de pesquisa. Assim, entrevistaram-se vários atores sociais, dentro da maior diversidade possível de gênero e classe, envolvendo tanto pessoas inseridas em setores organizados, como transeuntes e moradores do bairro. As pautas de entrevistas foram norteadas pelo desejo de compreender como os sujeitos interpretam as intervenções urbanas, inscrevendo os discursos na relação dialética tempo/espaço no atual contexto global.

\section{O espaço urbano e a lógica do capital}

Embora a aparência rígida dos espaços urbanos salte ao primeiro olhar, toda imobilidade contida no desenho citadino não passa de falseamento aos sentidos. As cidades são uma unidade arbitrária de representações e transitoriedades inscritas dialeticamente no tempo. Assim, a unidade tempo e espaço, como afirma Santos (1979), justifica o movimento como condição sine qua non da (re)composição urbana.

Desse modo, é inscrito na imbricação tempo/espaço que o sistema capitalista deve ser considerado componente crucial para entender o dinamismo urbano. Esse fato se justifica porque o espaço é condição para o processo produtivo, contemplando duas esferas: "de um lado a 
materialidade objetiva, e, de outro, um conteúdo social dado pelas relações sociais que se realizam num espaço-tempo determinado" (Carlos, 2014, p. 70). Portanto, a produção do espaço urbano é composta pela justaposição de aspectos da vida em sociedade: a dominação política, a acumulação do capital e a realização da vida humana (Carlos, 2014).

Para Lefebvre (1972), a dimensão espacial ganha relevância investigativa no momento em que se torna necessário compreender a reprodução do capital e as limitações impostas por suas crises cíclicas no atual contexto. $\bigcirc$ autor destaca que as cidades têm concentrado grande parte das atividades econômicas, o que faz dos centros urbanos cenários privilegiados dos efeitos mais díspares do sistema, tanto pela espacialização da desigualdade, como também pelo agravamento das formas assimétricas de existir socialmente.

Obviamente o que se pode observar é que a ação predatória do capital aprofunda a subsunção do espaço às necessidades de circulação de mercadorias e perpetuação da estrutura hegemônica. As cidades, então, se tornam palco para espetacularização e consumação da mercadoria, sendo, em grande parte, hierarquizadas e sistematizadas a partir das demandas de reprodução capitalista. À medida que os sujeitos mais se individualizam pela engrenagem produção/consumo, agravam-se as apropriações díspares do espaço, agudizando hierarquizações que cingem a grafia das cidades. Soma-se a isso o fato de que desequilibrios na distribuição de renda produzem apropriações desproporcionais do solo urbano, situação que torna as cidades um mosaico de demarcações dissemelhantes. Por conseguinte, "a produção da cidade comandada pelo econômico elimina aos poucos o sentido da cidade como obra, espaços de criação e gozo" (Carlos, 2011, p. 134).

Diante do exposto, fica evidente que o capital necessita ser representado espacialmente, de modo a garantir produção, circulação e consumo das mercadorias. É nesse teor que as cidades precisam ser construídas à imagem das demandas econômicas, ofertando condições favoráveis para perpetuar a lógica acumulativa e suplantando qualquer barreira que limite a reprodução do sistema. É por isso que alterações no espaço urbano são tão recorrentes, fato justificável pela própria dialética temporoespacial contida no dinamismo capitalista.

Um ambiente físico criado em um determinado momento no tempo deve atender as necessidades daquela sociedade naquele momento determinado, mas tornar-se-á antagônico no futuro, na medida em que a dinâmica do processo de acumulação e o crescimento da sociedade alteram as necessidades de valor de uso tanto do capital quanto do trabalho (Harvey, 1985,2 p. 173 apud Furtado, 2014, p. 341).

Nessa ação dinâmica de equalização contínua dos espaços urbanos às reconversões históricas do sistema capitalista, o poder público se torna agente direto na garantia da prevalência do projeto burguês para as cidades. Assim, com frequência projetos de requalificação são apontados como oriundos de interesses consensuais da população urbana, quando, na verdade, sua natureza consiste na legitimação dos interesses hegemônicos mais imediatos.

Embora o atual contexto seja tão caracterizado pela ação neoliberal, é válido ponderar que o ideário laisser-faire não prescinde totalmente a regulação estatal na economia, pelo contrário, o Estado frequentemente protagoniza a esfera econômica, sendo acionado para

2 Harvey, D. The urbanization of capital. Oxford: Basil Blackwell, 1985. 
mediar relações de poder e garantir os interesses do capital. Assim, é possível falar de mudanças nas funções do Estado com o amadurecimento do capitalismo, mas jamais poderíamos incorrer a ideia de extinção da participação dos governos. Assim, podemos entender que a ascensão e a perpetuação do sistema capitalista são assistidas "pela criação e transformações das instituições e funções estatais, satisfazendo as necessidades específicas do capitalismo. [...] De um modo ou de outro, o Estado capitalista precisa desempenhar suas funções básicas" (Harvey, 2005, p. 93). Nesse contexto, o Estado desempenha o importante papel de assegurar as condições para execução do ideário capitalista, especialmente na oferta da infraestrutura que sustente a produção/circulação/consumo da mercadoria.

Evidentemente, como sinalizamos no percurso teórico da presente pesquisa, a superestrutura econômica é porção fundamental para entender a dinâmica das cidades, mas não pode ser concebida como única. As cidades também são compostas de um universo complexo de memórias, relações de poder, representações e signos, afinal é sabido que existe uma quantidade imensurável de possibilidades de existir na urbe, por vezes subservientes, por vezes subversivas, ora capturadas por ideologias hegemônicas, ora (re)construídas por vivências que excedem normatizações éticas e estéticas. A cidade é também rebeldia incontida e anarquia grafada, cujos (des)caminhos são produto da coerção, mas também da contestação às formas hegemônicas.

espaço não pode ser reduzido apenas a uma localização ou às relações sociais da posse da propriedade - ele representa uma multiplicidade de preocupações sociomateriais. $\bigcirc$ espaço é uma localização física, uma peça de bem imóvel, e ao mesmo tempo uma liberdade existencial e uma expressão mental. $\bigcirc$ espaço é ao mesmo tempo o local geográfico da ação e a possibilidade de engajar-se na ação (Gottdiener, 2010, p. 127).

Essa ideia não aloca nosso percurso investigativo sobre a cidade para um campo idealista, desprovido de concretude, pelo contrário, apenas comprova nosso empenho em trazer para o rol de debates o fato de que nem todas as formas de existência urbana estão submissas à ideologia hegemônica. Noutros termos, concordamos que "o 'urbano' não é uma alma, um espírito, uma entidade filosófica” (Lefebvre, 2001, p. 55), mas são as redes sociais carregadas de ambivalências que, inscritas na dialética espaço/tempo, se materializam na complexa (e, por vezes, imprevisível) teia que se define por cidade.

\section{Gentrificação: ideologias materializadas no espaço}

Com a evolução do sistema capitalista no século XIX, a percepção do público como ambiente moralmente inferior ganhou força. Também nesse período a rua passou a ser designada como lugar de passagem, onde "pessoas de bem" estariam expostas ao contato com sujeitos de classe inferior. Até mesmo palavras como "arruaceiro" e "arruaça", por exemplo, passaram a corroborar essa ideia, quando o comportamento característico da rua foi associado ao desmando e à decadência. Por esse motivo, "a vontade de controlar e de moldar a ordem pública foi se desgastando, e as pessoas passaram a enfatizar mais o aspecto de se protegerem contra ela" (Nunes, 2001, p. 102). 
Evidentemente, fica implícita nessa percepção dicotômica uma ideologia disseminada pelos Estados no curso do capitalismo: a de que manifestações ganham as ruas são movidas pela vadiagem de sujeitos empenhados na infração da "ordem" consensualmente estabelecida. Diante disso, a ideia de público como lugar desordeiro se torna fecunda, nutrindo mais noções sobre a superioridade dos espaços privados, como muito difundida no século XX com advento da ideologia neoliberal.

Em concílio com essa ideia dicotômica público caótico x privado ordenado, gradualmente intervenções urbanas, oriundas de parcerias público-privadas, passaram a ser vistas com bons olhos pela população. Não raro uma logomarca de um conhecido banco é erigida numa praça pública indicando que chafarizes, árvores e ladrilhos estão sob seus cuidados, ou, ainda, grandes eventos populares nas ruas comumente são patrocinados por uma empresa de cerveja que estende letreiros luminosos fortemente projetados para despertar o desejo dos transeuntes. A racionalidade capitalista, então, adentra de tal modo os espaços que acirra as disputas, num contexto em que o gigantismo de signos de consumo denota a soberba hegemônica. Com isso, as cidades passam a concentrar uma quantidade perturbadora de emblemas, que escancaram a desarmonia das relações de poder no espaço público.

Seguindo o raciocínio aqui transcrito, é pertinente observar que, com grande frequência, os espaços públicos tendem a ser mais prontamente ordenados segundo interesses de sujeitos que detêm maior poder de contestá-los, não extinguindo camadas subalternizadas da sociedade, mas provocando higienização social nos ambientes mais disputados.

Os "melhoramentos" urbanos que acompanham o progresso da riqueza, a demolição de quarteirões mal construídos, a construção de palácios para bancos, lojas etc., o alargamento de ruas para o tráfego comercial e para as carruagens de luxo, o estabelecimento de linhas para bondes etc., - desalojam evidentemente os pobres, expulsando-os para refúgios cada vez piores e mais abarrotados de gente. (Marx, 1988, p. 764).

Embora Marx (1988) pontue o contexto citadino europeu do século XIX, a dinâmica excludente atual não se mostra tão diferente, pois os "melhoramentos urbanos" executados nos lugares públicos continuam atendendo aos interesses unilaterais de determinadas classes.

Notemos, por exemplo, os centros comerciais antigos de muitas cidades do mundo. Se originalmente estes foram considerados ambientes pomposos e preenchidos por classes nobres, à medida que se tornaram ruidosos e caóticos, muitos tenderam a ser repugnados pelas elites que tradicionalmente ali residiam. Enquanto os ricos migraram para bairros mais distantes do centro urbano, normalmente movidos por uma forte especulação imobiliária, os mais pobres, ou se apinham nas periferias imersas em problemas infraestruturais, ou recorriam aos cortiços nos centros antigos.

É também preciso acrescentar que os contínuos usos dos trechos urbanos mais tradicionais consagram suas paisagens como parte da identidade histórica urbana. É na prática social cotidiana que os sujeitos têm suas memórias empiricizadas na concretude espacial, o que torna alguns lugares uma espécie de síntese simbólica útil para coesão social. Desta feita, pode-se dizer que os centros urbanos antigos frequentemente contêm a materialmente 
signos importantes da história, expressos em monumentos, casarões, praças, teatros, coretos, feiras, estações e outros equipamentos que serviram de inspiração artística e de cenário para espetáculos, protestos ou tragédias historicamente relevantes.

Em Condição pós-moderna, Harvey (2001) apresenta contribuições importantes para esse tema. $\bigcirc$ autor adverte que muitos dos projetos urbanos empenhados na ordenação e controle do espaço foram traduzidos como uma espécie de projeto histórico. Afinal muitas administrações municipais refugiam no discurso patrimonialista como pretexto para o enobrecimento de áreas antigas da cidade. Harvey conclui que, num mundo marcado por valores efêmeros, a busca pela preservação do patrimônio histórico de uma sociedade sempre soa como proposta razoável, afinal "o espaço dá forte relevo ao vínculo potencial entre lugar e identidade social. Isso é patente na ação política" (Harvey, 2001, p. 272).

É muito recorrente perceber o quanto essas obras de revitalização, promovidas pelo governo, oportunizam a ação mais ostensiva do capital privado em determinados espaços públicos. Embora não queiramos adentrar nos amplos debates epistemológicos em torno dos conceitos de gentrificação (ou gentrification), recorreremos a este termo apenas como forma de sintetizar grosseiramente o fenômeno do enobrecimento de alguns espaços urbanos. Também sabemos que a gentrificação ocorre de muitas formas e que seria mais apropriado falar de gentrificações, dado às variáveis implícitas no fenômeno; porém o que queremos é encontrar um termo que dê conta de tratar das intervenções urbanas, que no cerne autenticam a mercantilização dos símbolos contidos no campo cotidiano das cidades. Soma-se a isso o fato de que os processos de gentrificação recorrentemente ocorrem em bairros tradicionais ou que tenham valoração histórica e simbólica mais expressiva, como em muito caracteriza o objeto de estudo que aqui pretendemos tratar.

Quando gentrificados, bairros terão deslocados "para a esfera do consumo os sentidos tradicionais da história e da cultura pública" (Leite, 2002, p. 119) e, consequentemente, serão definidos padrões estéticos equalizados ao projeto de enobrecimento do capital burguês. Em meio à população banida deste processo, a gentrificação tende a dividir opiniões, pois o discurso enaltece a geração de empregos, aumento da arrecadação por meio do turismo, além de prometer a melhoria da qualidade de vida geral da população; entretanto não se pode perder de vista que "o processo de gentrificação tornou-se um fim em si mesmo, um objetivo a ser atingido" (Siqueira, 2014, p. 397). Sobre esse fato, Smith destaca:

Na mídia, a gentrificação tem sido apresentada como o maior símbolo do amplo processo de renovação urbana que vem ocorrendo [...] Quaisquer que sejam as reais forças econômicas, sociais e políticas que pavimentam o caminho para a gentrificação, e quaisquer que sejam os bancos e imobiliárias, governos e empreiteiros que estão por trás do processo, o fato é que a gentrificação aparece, à primeira vista, e especialmente nos EUA, como um maravilhoso testemunho dos valores do individualismo, da família, da oportunidade econômica e da dignidade do trabalho. Aparentemente, ao menos, a gentrificação pode ser tocada de forma a executar alguns dos acordes mais ressonantes de nosso piano ideológico (Smith, 2007, p. 18). 
Concordando com Serpa (2014), que entende a produção do espaço como um fenômeno material e simbólico, os processos de gentrificação necessitam também operar, tanto no campo concreto, como na esfera simbólica. Por isso, como produto, a gentrificação acentua a estratificação social dos territórios urbanos, demarcando mais claramente a disparidade entre as formas de uso do espaço. Nesse teor, fronteiras se tornam mais visíveis, tanto por conta da higiene social, como por causa da seleção de determinados nichos de consumo. Aqui, a cultura e a cidade são consideradas mercadorias, comercializadas em espaços de grife.

A competição entre cidades por turistas ou empreendedores estrangeiros é acirrada e as municipalidades se empenham para melhor vender a imagem de marca da sua cidade, em detrimento das necessidades da própria população local, ao privilegiar basicamente o visitante estrangeiro, através de seu maior chamariz, o espetáculo. $\bigcirc$ patrimônio cultural urbano passa, assim, a ser visto como uma reserva, um potencial de espetáculo a ser explorado (Jacques, 2003, p. 82).

A lógica é criar cenários a partir de uma arquitetura-espetáculo, que mercantilizem identidades culturais diluídas na história da população. Como as dimensões material e simbólica interpenetram-se continuamente, os resultados das empreitadas enobrecedoras do espaço impactam também as representações dos sujeitos que trafegam por esses locais. Logicamente, os processos de gentrificação são anuídos por relações desiguais de poder, que, por efeito, intensificam disputas simbólicas na cidade. Por conta de uma clara exclusão de expressiva parcela da população local, impedida de interagir com esses espaços-mercadoria, "são criadas pelos não usuários zonas de tensão pela disputa prática e simbólica da cidade" (Leite, 2010, p. 83).

É nesse contexto que o Estado precisa explicitar seu poder coercitivo de modo a garantir a "ordem" nos lugares gentrificados. Sistemas de vigilância e guarda são fortemente implantados nesses locais, policiamento tende a ser redobrado, além de formas outras de garantir o "bom comportamento" dos frequentadores, agora coagidos a harmonizarem suas posturas com a nova indumentária dos espaços.

Muito embora a parafernália de vigilância e punição seja instalada nos espaços gentrificados, não podemos negligenciar que formas de subversões ainda são possíveis de ser eclodidas. $\bigcirc$ panóptico não consegue dar conta de anular a resistência e impor uma plena subsunção dos sujeitos às formas autoritárias de apropriação dos lugares, afinal "as práticas sociais espacializam em vez de se localizarem no âmbito de alguma malha repressiva de controle social" (Harvey, 2001, p. 197).

Nesse sentido, reconhecemos sim que os processos de gentrificação operam numa base unilateral, de favorecimento da classe hegemônica, expressando a tentativa do capital de criar uma paisagem social e física da sua própria imagem (Harvey, 2014). Todavia, o que queremos chamar atenção é para o fato de que o espaço seja também uma "liberdade existencial e uma expressão mental" (Gottdiener, 2010, p. 127) e, assim sendo, contém formas distintas de representação e concepção. Não raro testemunharmos pichações, confrontos, protestos, atos de vandalismo ou insistentes apropriações subversivas de redutos, enunciando a desobediência aos padrões arbitrariamente instituídos. 


\section{O projeto burguês para a boemia do Rio Vermelho}

Foi em meados do século XIX que Engels já mencionava a situação deplorável dos subúrbios nas cidades inglesas.

Todas as grandes cidades possuem um ou vários "bairros de má reputação" onde se concentra a classe operária. É certo que é frequente a pobreza morar em vielas escondidas, muito perto dos palácios dos ricos, mas, em geral, designaram-lhes um lugar à parte onde, ao abrigo dos olhares das classes mais felizes, tem de se safar sozinha, melhor ou pior. (Engels, 1985, p. 38).

Quase dois séculos depois, as palavras do autor parecem perturbadoramente atuais. A higienização da pobreza em bairros nobres é uma prática extremamente comum, que ocasionalmente conta com a participação estatal. Na cidade de Salvador, esta é uma prática histórica bem visível na configuração espacial.

A Revista Redobra publicou em 2012 um capítulo de artigo intitulado "Mário Leal ou as favelas" (Jacques, 2014), no texto a autora se empenha em expressar, por meio de relatos jornalísticos e outras fontes históricas, como a população de Salvador demonstrava repugnância à urbanização favelizada. Essa realidade ganhou ainda mais fôlego com a assinatura do contrato entre a prefeitura de Salvador e o engenheiro Mário Leal Ferreira, ${ }^{3}$ no ano de 1943. Ao escritório de urbanismo do referido engenheiro foi delegada a incumbência de elaborar a Tese de Habitação Proletária, que previa direcionar um tratamento à população pobre. $\bigcirc$ decreto destinava as áreas do município para ocupação de camadas com menor poder aquisitivo, com objetivo de salvaguardar territórios mais nobres da presença inconveniente das favelas.

A ideia de extinguir a miséria do perímetro urbano tinha nas entrelinhas a concepção de que as paisagens privilegiadas da orla deveriam ser desfrutadas por uma classe específica. Por isso, a intenção seria garantir uma cidade "limpa" da pobreza, impedindo o contraste entre o patrimônio arquitetônico urbano dos bairros mais centrais com a pobreza dos casebres e mocambos. Estado se tornou parceiro do sonho das classes dirigentes em Salvador: "uma cidade limpa ou pelo menos onde a favela estivesse sob o controle do poder público" (Jacques et al., 2014, p. 102).

Como resultado, as favelas soteropolitanas ainda hoje são invisibilizadas em pontos turísticos da cidade. Bairros marcados pela movimentação cultural de Salvador, a exemplo de Barra, Rio Vermelho ou partes do Centro Histórico, não ficam tão nitidamente entremarcados por favelas. Apenas com muito custar, os casebres se tornam visíveis no horizonte, entre dois prédios, ou escondido atrás de um casarão tombado. Para um turista desavisado transitando no Rio Vermelho, as favelas que cercam o bairro parecem inexistir. A limpeza social, e consequentemente étnica, é realidade histórica na cidade de Salvador.

A Lei Municipal n. 5.245, de 05 de fevereiro de 1997, decretada pelo então prefeito João Henrique, instituiu a Fundação Mário Leal Ferreira (FMLF) em substituição ao Centro de Planejamento Municipal (COM). Entre outros atributos tratados, o regimento

3 Ironicamente, a fundação hoje responsável pela requalificação da orla de Salvador recebe o nome do urbanista Mário Leal Ferreira, comprovando a perpetuação da mesma ideologia higienista de outrora. 
da Fundação elenca um especificamente no Capítulo II, Artigo 20, Inciso I: "Elaboração, coordenação e acompanhamento de projetos urbanísticos, de desenho urbano e setorial em segmentos do espaço urbano bem como nos espaços de valor simbólico, histórico e sociocultural" (Salvador, 2009, p. 4).

Para garantir a execução da atividade acima tratada, o mesmo regimento em seu artigo 30 define que a Fundação poderá "articular-se com órgãos e entidades da Administração Pública Federal, Estadual e Municipal, no âmbito de sua área de atuação, inclusive celebrar convênios, contratos e acordos com instituições públicas e privadas, nacionais, estrangeiras e internacionais" (Salvador, 2009, p. 4-5, grifos nossos).

Ao registrar a parceria público-privada como pressuposto para elaboração de projetos urbanísticos, a lei abre a prerrogativa para que o espaço urbano municipal seja alvo de fortes interesses especulativos do capital privado. Desse modo, a FMLF tem em sua gênese o nexo higienista historicamente contido na urbanização soteropolitana, nítido, tanto no regimento que a institucionaliza, como no perfil ideológico do urbanista que a nomeia.

Tal discursão é útil para problematizar o objeto de estudo que aqui nos interessa porque é essa a Fundação que se tornou responsável pela requalificação do Rio Vermelho no ano de 2014, valendo uma especial atenção ao antigo Mercado do Peixe, renomeado para Vila Caramuru.

Situado no centro da boemia do Rio Vermelho, o Mercado do Peixe era composto de comerciantes populares que possuíam uma licença temporária para uso do espaço. Contudo, foi no ano de 2015 que a situação começou a ser profundamente alterada. Após terem vencido licitação, duas empresas privadas passaram a administrar o lugar, impondo um severo processo de requalificação e elevando substancialmente os valores de locação dos quiosques. ${ }^{4}$

As condições se tornaram hostis para os antigos negociantes, uma vez que as exigências estéticas e os valores de locação se tornaram muito onerosas. Permaneceram apenas quatro dos antigos comerciantes, que tinham reserva de capital para investir nas adequações às novas exigências contratuais, cujos investimentos ultrapassaram os 250 mil reais, somado ao pagamento de aluguel e condomínio. Os velhos botecos foram substituídos por sorveterias, elegantes bares de cardápio variado e restaurantes de comida baiana, todos devidamente requalificados dentro do padrão paisagístico da área.

Agora renomeada Vila Caramuru, a área gourmet está sob concessão privada de duas empresas, que por quinze anos, estarão incumbidas de locar as lojas e administrar financeira e estruturalmente o lugar. $\bigcirc$ comércio também passou a ser regrado, pois, tendo adquirido direito de exclusividade, a cervejaria Itaipava é a única marca de bebida que pode ser vendida na área (Pacheco, 2016). Ademais, serviços de limpeza e vigilância estão sob os cuidados das concessionárias, permitindo ordenar a frequência e a circulação nas imediações e no interior do espaço.

4 antigo Mercado do Peixe, que funcionava há quase 50 anos, possuía 36 boxes. Hoje, a Vila Caramuru oferece apenas 11 espaços para restaurantes, todos já ocupados por empreendedores do ramo. 
Figura 4 - A Vila Caramuru, antigo Mercado do Peixe, foi uma área intensamente enobrecida, com a instalação de restaurantes segundo o conceito gourmet, sob o ordenamento de empresas que hoje detêm a concessão administrativa do lugar

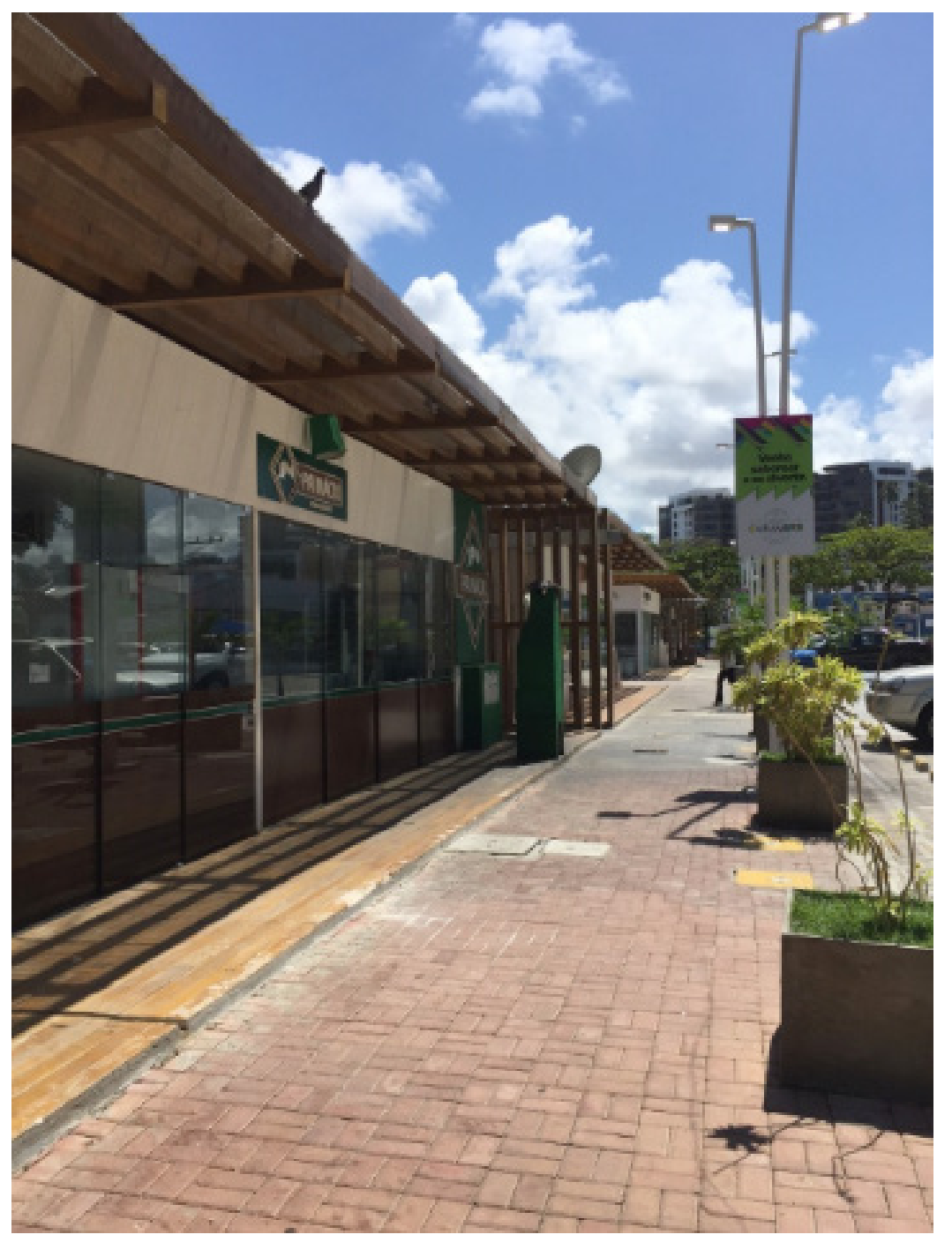

fonte: Acervo pessoal.

Embora saibamos que a privatização explícita da Vila Caramuru tenha resultado na expulsão clara de comerciantes populares para introdução de uma área gourmet enobrecida, no discurso de alguns essas mudanças ecoam de modo positivo. Algumas falas confirmam a ideia:

Tinha muita droga, muito roubo e prostituição naqueles botecos do Mercado do Peixe. Gente de bem já não ia mais lá (Antônio, 50 anos).

Os maconheiros espantavam turistas. Eu mesmo não levaria minha família naquele velho Mercado do Peixe. Agora está limpo, tem vigilância e comida boa (João, 40 anos).

$O$ antigo Mercado do Peixe estava muito inseguro. E aqueles botecos eram sujos e só atraiam malandros. Hoje até o prefeito vem morar aqui do lado (Sérgio, 45 anos). 


\section{Figura 5 - Antigo Mercado do Peixe em meados dos anos 1990. Área usada por comerciantes populares que foi recentemente elitizada por obras do poder público}

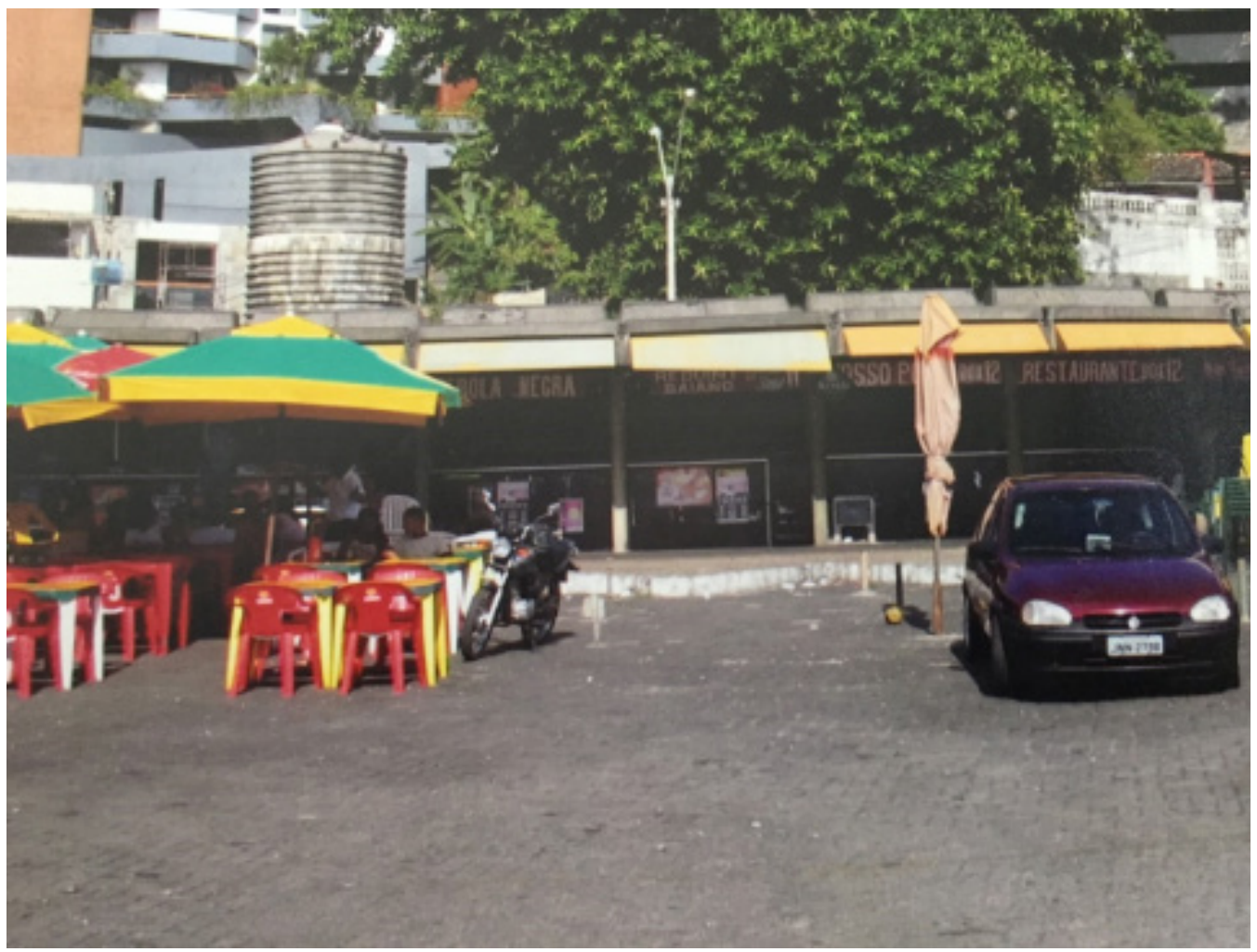

fonte: Acervo Museu Jorge Amado.

É preciso registrar que as obras no bairro dividiram opiniões, tanto entre os moradores locais, como também em meio à população geral da cidade. Escrevemos este artigo no período de campanha política dos candidatos à prefeitura municipal e, muito embora não tenhamos o discurso partidário como objeto de pesquisa neste texto, não há como ignorar o fato de que Antônio Carlos Magalhães Neto tenha sido reeleito em primeiro turno neste ano de 2016 com $73,99 \%$ dos votos. Herdeiro da ideologia carlista, ${ }^{5}$ ACM Neto perpetua traços da política historicamente implantada pelo grupo a que pertence, fortemente caracterizado por ações autoritárias e populistas.

$\bigcirc$ trecho transcrito acima revela a sensação de orgulho do entrevistado ao citar que "até o prefeito vem morar aqui ao lado", ele aponta para um suntuoso edifício de alto padrão recentemente construído no Morro do Conselho. Ora, ao conjecturar sobre a proximidade distante do prefeito, momentaneamente o entrevistado esquece que o elegante residencial com vista privilegiada, demarca um território próximo geograficamente, mas longínquo economicamente. De alguma forma, a suposta proximidade ao prefeito parece emitir uma sensação de conforto e acalento advindos da modelo populista que caracteriza o grupo político em questão. É como se nas entrelinhas coubesse a ideia de que "se até ele vem, é porque vale a pena estar aqui".

5 Referência ao ex-prefeito de Salvador, ex-governador e ex-senador do estado da Bahia, Antônio Carlos Magalhães, também avô do atual prefeito da cidade. 
Todavia, mesmo diante de medidas tão personalistas, a reeleição de ACM Neto com índices tão expressivos denota a popularidade da política por ele perpetrada. Mas, como justificar uma aceitação tão massiva, quando intervenções claramente elitistas expulsaram contingentes tão representativos da população de baixa renda? Richard Sennett tem uma tese bastante intrigante para problematizar esta questão. Para ele:

O líder carismático moderno destrói qualquer distanciamento entre os seus próprios sentimentos e impulsos e aqueles de sua plateia, e desse modo, concentrando os seus seguidores nas motivações que são dele, desvia-os da possibilidade de que o meçam por seus atos (Sennett, 2014, p. 381).

\section{E disso deduz que:}

As estruturas de dominação permanecem particularmente incontestadas quando as pessoas são levadas a eleger políticos que parecem coléricos, como se estivessem prontos a transformar as coisas. Tais políticos estão liberados, pela própria alquimia da personalidade, de traduzir seus impulsos coléricos em ação (Sennett, 2014, p. 382).

Na tentativa de demonstrar-se eficaz, o líder carismático investe esforços em intervenções de ampla visibilidade. Obras monumentais no espaço urbano, então, ofuscam a realidade perversa à medida que espetaculariza pelo mascaramento arquitetônico. Soma-se a isso o autoritarismo do líder carismático que, como trata Sennett, traduz impulsos coléricos em ação e, dessa forma, convence as massas de que a peleja por interesses pessoais consiste numa defesa veemente do interesse coletivo.

Disso resulta que as intervenções urbanas autoritárias no governo de ACM Neto, combinadas à imagem populista do prefeito, parecem falsear o caráter classista das políticas implementadas na cidade, com o encobrimento dos resultados mais cruéis obtidos por medidas higienistas.

Outra característica contida no discurso político do grupo perpetuado no poder, é a desqualificação de espaços públicos pelo abandono. Como frequentemente perceptível na ação de políticas neoliberais, o sucateamento do patrimônio público é etapa crucial para justificar as intervenções amplamente gerenciadas por grupos empresariais. Por conseguinte, é por meio do abandono que governos conseguem convencer a população de que as concessões ao capital privado são única possibilidade para garantir a preservação do patrimônio. Neste contexto, as cidades se tornam lócus para consumação do projeto protagonizado por grupos hegemônicos, com o engendramento de discursos partidários garantidores dos interesses sectários do grande capital.

Assim, seguindo o pretexto da requalificação pela desqualificação de tudo o que é público, o Rio Vermelho nos últimos anos já demonstrava fortes traços de abandono, com áreas de lazer arruinadas, ciclovias esburacadas, praças depredadas, iluminação vandalizada, além do mercado desgastado pelos usos exaustivos. A ruína estrutural dos equipamentos públicos no bairro era ainda mais repugnada quando preenchida pela população de baixa renda. Enquanto ambulantes e consumidores de pequeno poder aquisitivo perambulavam pelo Rio Vermelho, empresários da rede hoteleira, investidores do setor turístico e alguns moradores objetavam a popularização da orla do bairro, especialmente movidos pelo argumento da desvalorização imobiliária e do potencial turístico local subaproveitado pelo grande capital. 
Énesse cenário de tensionamento das relações sociais, que a prefeiturainiciou asintervenções objetivando atender aos interesses de grupos socialmente privilegiados. As reformas rapidamente se mostraram tão claramente elitistas que os canais de interlocução foram rapidamente silenciados, furtando o direito popular de participação nas decisões tomadas pelo poder público. Alguns meses após a inauguração da primeira etapa das reformas, persistia a deficiência no escoamento de águas pluviais, prosseguia a lentidão no trânsito e perpetuavam os índices de violências em mediações do bairro, denunciando o pouco compromisso das reformas com a qualidade de vida geral da população. As palavras de alguns moradores ${ }^{6}$ corroboram o que tratamos:

Outro aspecto delicado é a forma como a reforma foi feita, com pouco cuidado com os moradores e comerciantes, sem nenhum cuidado com pedestres, nem com a relocação de pontos de ônibus - como acontece agora na praça Brigadeiro Faria, fechando dois pontos de ônibus e desativando um semáforo numa via onde há grande fluxo de pedestres, sem garantir nenhuma segurança para os transeuntes (Silvia, 37 anos).

O foco não estava no morador do bairro, mas sim, em criar um espaço turístico, voltado aos holofotes e propício a realização de eventos, como tem acontecido no Largo da Mariquita, que foi milimetricamente pensado para acolher shows, festival da primavera e, mais recentemente, um trio para a comemoração da reeleição do prefeito (Roberto, 38 anos).

Como reincidente nos processos de gentrificação, as intervenções realizadas no Rio Vermelho trataram de questões superficiais, num mascaramento de conflitos contidos na vida dos sujeitos que residem e trafegam no bairro. Portanto, a aparência ostentosa do Rio Vermelho não garantiu a inserção dos sujeitos, não implicou em melhoria da vida e, consequentemente, não foi balizada por estratégias emergenciais voltadas à inserção da população de baixa renda. Basta transcender a superfície maquiada do bairro para vislumbrar as entrelinhas das reformas urbanas, cujas motivações hierarquizadas desvendam políticas públicas gerenciadas pelo grande capital. Sobre isso, seguem os relatos de dois entrevistados:

Temos espaços cada vez mais segregados. Os pescadores da colônia perderam o suporte de refeições financeiramente acessíveis, sendo ainda mais pressionados. Estes foram relatos que ouvi in loco de alguns deles. Fora isso, toda a população do Vale das Pedrinhas, Nordeste e Vila Matos, que encontrava no mercado do peixe uma alternativa de lazer, perdeu seu espaço. Algumas casas culturais, que garantiam mais diversidade nas atividades do bairro, fecharam (Roberto, 38 anos). Eu não consigo ver nenhum ponto positivo nessa obra. Primeiro pela descaracterização do bairro, pois a prefeitura ignorou o fato de o Rio Vermelho estar dentro de uma poligonal de tombamento, resultando na perda de áreas verdes para ceder espaço à circulação de veículos além de outras descaracterizações feitas em lugares históricos [...] A participação popular foi anulada, com retirada de pretos e pobres e inserção de brancos e ricos [...] Tínhamos realmente problemas de pavimentação e acessibilidade que foram parcialmente resolvidas (Pedro, 29 anos).

6 Alguns moradores entrevistados integram o movimento organizado de oposição às reformas do Rio Vermelho. 


\section{A requalificação pela desqualificação: possibilidades de resistência}

Quando inaugurada parte das intervenções no Rio Vermelho, a administração municipal insistiu no uso do adjetivo "novo" para se referir ao bairro requalificado. Esse discurso insiste em fundamentar a requalificação, desqualificando o "velho" Rio Vermelho. Ideologia muito semelhante à lógica do vocábulo "revitalização", cuja semântica insinua a devolução da "vida" ao estado ruinoso de uma área abandonada. Aqui, "vida" é, portanto, atributo enxertado pela ideologia capitalista, mediante a sincronia da dinâmica urbana ao modus operandi do sistema. Ou seja, quanto mais inóspito aos interesses de grupos hegemônicos, maior a necessidade de "revitalizar" ou "requalificar" determinada área urbana, de modo a sobrepujar qualquer força limitadora à fluência do capital.

Evidentemente, essa lógica negligencia as muitas possibilidades de apropriação e subversão da cidade, sobretudo porque os descaminhos do capital ora monumentalizam áreas, ora as abandonam para atender ao percurso cambiante da especulação. Ademais, a ideologia da requalificação urbana, como conferida ao Rio Vermelho, ocorre mediante a apropriação do potencial empreendedor de determinadas áreas, negligenciando a cidade como um espaço de direito também das camadas menos favorecidas. Esse esquema se apoia na ideia de cidade-empresa, em que apenas investidores e consumidores são bem-vindos, objetivando enaltecer o lucro como meta prioritária de políticas públicas.

Diante disso, muito embora o discurso neoliberal insista em nos convencer de que a vida urbana se baseia num embate de forças individuais, os movimentos de resistência não podem prescindir o fato de que o direito à cidade deve ser um meio de contestação coletiva. Logo, o direito à cidade não pode ser entendido como "um direito condicional de acesso àquilo que já existe, mas sim um direito ativo de fazer a cidade diferente [...], uma maneira alternativa de simplesmente ser humano" (Harvey, 2014, p. 58).

Destarte, esta pesquisa pôde reforçar a ideia de que as intervenções gentrificadoras no Rio Vermelho reiteram os objetivos unilaterais do projeto burguês para a cidade que, em parceria com os Estados, imprimem caracteres associados à busca visceral pela perpetuação do sistema. Como verificado em outras cidades do mundo, as identidades culturais aqui também são dissimuladas como ocasião para endossar o enobrecimento de áreas urbanas, tornando o espetáculo um meio de sedução pelo "disfarce do livre-arbítrio, em vez de revelar-se como força externa” (Bauman, 2001, p. 110).

\section{Referências}

BAUMAN, Z. Modernidade líquida. Tradução de Plínio Dentzien. Rio de Janeiro: Zahar, 2001.

CARLOS, A. F. A. Da organização à "produção" do espaço no movimento do pensamento geográfico. In: CARLOS, A. F. A.; SOUZA, M. L. S; SPOSITO, M. E. B. (Org.). A produção do espaço urbano: agentes e processos, escalas e desafios. 3. ed. São Paulo: Contexto, 2014. p. 53-73. 
A condição espacial. São Paulo: Contexto, 2011.

ENGELS, F. A situação da classe trabalhadora na Inglaterra. Tradução de Rosa Camargo Artigas, Reginaldo Forti. São Paulo: Global, 1985.

FURTADO, C. R. Intervenção do Estado e (re)estruturação urbana. Um estudo sobre gentrificação. Cadernos Metrópole, São Paulo, v. 16, n. 32, p. 341-364, nov. 2014. Disponível em: http://www.scielo.br/pdf/cm/v16n32/2236-9996-cm-16-32-0341.pdf. Acesso em: 28 jul. 2016.

GOOGLE Maps. Disponível em: https://www.google.com/maps/. Acesso em: 10 out. 2016.

GOTTDIENER, M. A produção social do espaço urbano. São Paulo: Edusp, 2010.

HARVEY, D. A liberdade da cidade. In: VAINER, C. et. al. Cidades rebeldes: passe livre e as manifestações que tomaram as ruas do Brasil. São Paulo: Boitempo, 2014. p. 47-61.

A produção capitalista do espaço. Tradução de Carlos Szlak. São Paulo: Annablume, 2005.

Condição pós-moderna. Tradução de Adail Ubirajara Sobral, Maria Stela Gonçalves. São Paulo: Loyola, 2001.

JACQUES, P. B. Patrimônio cultural urbano: espetáculo contemporâneo?. Revista de Urbanismo e Arquitetura, Salvador, v. 6, n. 1, p. 32-39, 2003. Disponível em: https:// repositorio.ufba.br/ri/handle/ri/1368. Acesso em: 30 jul. 2016.

et al. Salvador, cidade do século XX: a partir das memórias de Pasqualino Romano Magnavita. Revista Redobra, Salvador, v. 14, p. 89-131, 2014. Disponível em: http:// www.redobra.ufba.br/. Acesso em: 7 out. 2016.

LEFEBVRE, H. O direito à cidade. Tradução de Rubens Eduardo Frias. São Paulo: Centauro, 2001.

O pensamento marxista e a cidade. Tradução de Jehovanira de Souza. São Paulo: Ulisseia, 1972.

LEITE, R. P. A exaustão das cidades: antienobrecimento e intervenções urbanas em cidades brasileiras e portuguesas. Revista Brasileira de Ciências Sociais, São Paulo, v. 25 , n. 72, fev. 2010. Disponível em: http://www.scielo.br/pdf/rbcsoc/v25n72/v25n72a06. pdf Acesso em: 30 jul. 2016.

. Contra-usos e espaço público: notas sobre a construção social dos lugares na Manguetown. Revista Brasileira de Ciências Sociais, São Paulo, v. 17, n. 49, jun. 2002. Disponível em: http://www.scielo.br/scielo.php?script=sci_arttextEpid =S0102-69092002000200008. Acesso em: 30 jul. 2016.

MARX, K. O Capital. Tradução de Reginaldo Sant'Anna. 12. ed. Rio de Janeiro: Bertrand Brasil, 1988. v. 1: livros I e II.

NUNES, J. H. O espaço urbano: a "rua" e o sentido público. In: ORLANDI, E. P. (Org.). Cidade atravessada: os sentidos públicos no espaço urbano. Campinas: Pontes, 2001. p. 101-110. 
PACHECO, C. Novo Mercado do Peixe reabre essa semana com 11 novos restaurantes. Correio, Salvador, 14 ago. 2016.

PREFEITURA MUNICIPAL DE SALVADOR. Orla Salvador. Disponível em: http://www.novaorla. salvador.ba.gov.br/index.php/rio-vermelho. Acesso em: 8 out. 2016.

SALVADOR. Decreto n. 19.402 de 18 de março de 2009. Aprova o Regimento da Fundação Mário Leal Ferreira (FMLF), e dá outras providências. Gabinete do Prefeito Municipal de Salvador, mar. 2009. Disponível em: http://fmlf.salvador.ba.gov.br/images/Organograma_e_Regimento. pdf. Acesso em: 14 ago. 2016.

SANTOS, M. Espaço e sociedade. Petrópolis: Vozes, 1979.

SENNETT, R. O declínio do homem público. Tradução de Lygia Araujo Watanabe. Rio de Janeiro: Record, 2014.

SERPA, A. Lugar e centralidade em um contexto metropolitano. In: CARLOS, A. F. A. et al. (Org.). A produção do espaço urbano: agentes e processos, escalas e desafios. São Paulo: Contexto, 2014. p. 123-146.

SIQUEIRA, M. T. Entre o fundamental e o contingente: dimensões da gentrificação contemporânea nas operações urbanas em São Paulo. Cadernos Metrópole, São Paulo, v. 16, n. 32, p. 391416, nov. 2014.

SMITH, N. Gentrificação, a fronteira e a reestruturação do espaço urbano. Tradução de Daniel de Melo Sanfelici. Geousp - Espaço e Tempo, São Paulo, n. 21, 2007. Disponível em: http:// www.geografia.fflch.usp.br/publicacoes/Geousp. Acesso em: 7 out. 2016. 